\title{
DIRECT MOLECULAR AND SPECTROSCOPIC EVIDENCE FOR INCREASED AMMONIA REMOVAL CAPACITY OF SKELETAL MUSCLE IN ACUTE LIVER FAILURE
}

\author{
Nicolas Chatauret, Paul Desjardins, Claudia Zwingmann, Christopher Rose, K.V. \\ Rama Rao, Roger F. Butterworth,
}

Neuroscience Research Unit, University of Montreal (CHUM), Hôpital Saint-Luc, 1058 St-Denis Street, Montreal, Que., Canada $\mathrm{H} 2 \mathrm{X} 3 \mathrm{~J} 4$

\section{ABSTRACT}

Background/Aims It has been proposed that, in acute liver failure, skeletal muscle adapts to become the principle organ responsible for removal of blood-borne ammonia by increasing glutamine synthesis, a reaction that is catalyzed by the cytosolic ATP-dependent enzyme glutamine synthetase. To address this issue, glutamine synthetase expression and activities were measured in skeletal muscle of rats with acute liver failure resulting from hepatic devascularization. Methods Glutamine synthetase protein and gene expression were investigated using immunoblotting and semi-quantitative RT-PCR analysis. Glutamine synthetase activity and glutamine de novo synthesis were measured using, respectively, a standard enzymatic assay and $\left[{ }^{13} \mathrm{C}\right]$-nuclear magnetic resonance spectroscopy. Results Glutamine synthetase protein (but not gene) expression and enzyme activities were significantly up-regulated leading to increased de novo synthesis of glutamine and increased skeletal muscle capacity for ammonia removal in acute liver failure. In contrast to skeletal muscle, expression and activities of glutamine synthetase in the brain were significantly decreased. Conclusions These findings demonstrate that skeletal muscle adapts, through a rapid induction of glutamine synthetase, to increase its capacity for removal of blood-borne ammonia in acute liver failure. Maintenance of muscle mass together with the development of agents with the capacity to stimulate muscle glutamine synthetase could provide effective ammonia-lowering strategies in this disorder.

Keywords Acute liver failure; Skeletal muscle; Ammonia; Glutamine; Glutamine synthetase; Nuclear magnetic resonance spectroscopy; Brain edema

\section{INTRODUCTION}

Circulating ammonia concentrations in the 250-600 $\mu \mathrm{M}$ range have consistently been reported in both experimental and human acute liver failure (ALF) and increased arterial ammonia concentrations have been proposed as a predictor of brain herniation and mortality in ALF patients [1]. Brain ammonia may reach millimolar concentrations in ALF and such concentrations are well established to have deleterious effects on cerebral metabolism and function [2].

Under normal physiological conditions, ammonia detoxification relies almost exclusively on hepatic urea and glutamine synthesis by periportal and perivenous hepatocytes, respectively. ALF resulting from either toxic liver injury or viral hepatitis results in a serious compromise of hepatocyte integrity with consequent increases of circulating ammonia. A number of studies have provided evidence that skeletal muscle becomes the major organ responsible for removal of excess blood-borne ammonia in cirrhotic patients [3] as well as in animal models of chronic liver failure [4] and [5]. However, evidence that a similar response occurs in ALF is limited. 
The objective of the present study was the assessment of the capacity of skeletal muscle compared to brain (a second organ with the potential to remove ammonia) to increase its capacity to remove increased blood-borne ammonia in ALF. Four approaches based upon molecular, spectroscopic and hemodynamic measurements were undertaken namely (1) Measurement of glutamine synthetase (GS) mRNA and protein, (2) measurement of GS enzyme activities, (3) measurement of ammonia and glutamine metabolic fluxes and (4) direct spectroscopic measurement of de novo glutamine synthesis in experimental ALF. The devascularized rat model of ALF was used for the studies described since this model recapitulates the pathologic, metabolic and neurologic features of human ALF including sustained hyperammonemia, loss of perivascular and periportal hepatocytes and neurological manifestations such as brain edema and encephalopathy [6]. Studies were undertaken $6 \mathrm{~h}$ following hepatic devascularization, prior to the onset of brain edema or severe encephalopathy in order to minimize confounding effects of these complications on cerebral metabolism.

\section{MATERIAL AND METHODS}

\section{Animal surgery}

Male Sprague-Dawley rats (175-200 g) were anesthetized with isoflurane, and an end-to-side portacaval anastomosis was performed according to the guidelines of Lee and Fisher [7] and as previously described [8]. Total surgery time was $<15 \mathrm{~min}$. Sham-operated control rats, matched for weight, were similarly anesthetized and the portal vein was clamped for $15 \mathrm{~min}$. Following surgery, all animals were individually housed with free access to food and water under constant conditions of temperature, humidity, and light cycles.

Twenty-four hours after portacaval anastomosis or laparotomy, rats were reanesthetized and subjected to hepatic artery ligation (HAL) and all animals were sacrificed $6 \mathrm{~h}$ after HAL. All surgical procedures were performed in accordance with the Guidelines of Canadian Council of Animal care and were approved by Animal Research Committee of CHUM.

\section{Measurement of organ blood flow}

Six hours post-HAL or sham operation, animals were anesthetized with isoflurane and body temperature was maintained at $37^{\circ} \mathrm{C}$ with a CMA 150 temperature controller (CMA microdialysis, Stockholm, Sweden). A PE-10 catheter (Intramedic Clay Adams, Becton Dickinson, Sparks, MD) was placed in the right carotid artery and advanced into the left ventricle as previously described [9]. Correct positioning in the left ventricle was verified by hemodynamic monitoring. A PE-50 catheter (Intramedic Clay Adams, Becton Dickinson, Sparks, MD) was placed in the left femoral artery. Total time for catheter placement was less than 15 min.

Blood flow was measured using the radioactive microsphere technique as previously described [10]. Before sacrifice $1-1.2 \times 10^{5}$ microspheres $\left(15 \pm 2 \mu \mathrm{m}\right.$ ) labeled with ${ }^{85} \mathrm{Sr}$ (Perkin-Elmer, Boston, MA) in $0.7 \mathrm{~mL}$ of saline $0.05 \%$ tween 80 (Sigma Aldrich, St Louis, MO) were sonicated for $30 \mathrm{~min}$ and injected over a $15 \mathrm{~s}$ period into the left ventricle to determine the hind limb muscle blood flow. Just before injection, withdrawal of blood from the femoral arterial catheter was started at a rate of $0.786 \mathrm{~mL} / \mathrm{min}$ (Harvard pump, Mills, MA) and collected in a heparinized glass syringe for a total time of $1.25 \mathrm{~min}$.

At sacrifice, left and right kidneys, and right hind limb muscles (posterio-medial and lateral thigh, muscles) were rapidly removed, weighed, pooled and counted. Right and left renal blood flow and skeletal muscle flow were calculated from the radioactivity measured in those tissues using a gamma counter according to the formula described previously [11]

Agreement between right and left kidney flow ( $\leq 20 \%$ difference) indicated adequacy of the microsphere injection. 
Chatauret, N. et al., 2006. Direct molecular and spectroscopic evidence for increased ammonia removal capacity of skeletal muscle in acute liver failure. Journal of Hepatology, 44(6), p.1083-1088.

\section{Tissue sampling for arterio-venous differences}

Following the microsphere procedure, femoral veins and arteries of the right hind limb were exposed, arterial and venous blood samples were taken by heparinized syringes ( $1 \mathrm{~mL}, 25 \mathrm{G}$ needle). Arterial and venous blood of $0.5 \mathrm{~mL}$ was taken and immediately centrifuged to separate the plasma for determination of arterio-venous differences for ammonia and glutamine across the right hind limb.

\section{Measurement of plasma ammonia}

Plasma ammonia levels were measured using a commercial ammonia test kit, based on an ion exchange method, followed by colorimetric measurement of ammonia nitrogen with the Bertholet phenate-hypochlorate reaction [12].

\section{Measurement of plasma glutamine}

Glutamine concentrations were measured in femoral arterial and venous plasma samples using a Perkin-Elmer reverse phase HPLC system with fluorescence detection and precolumn $o$-phthalaldehyde derivatization, as previously described [13].

\section{Measurement of tissue glutamine synthetase activity}

Groups of rats were sacrificed by decapitation. Brains were rapidly removed and dissected on ice and $1 \mathrm{~g}$ of posteriomedial and lateral thigh muscle was snap frozen. All tissue samples were stored at $-70{ }^{\circ} \mathrm{C}$ until use. Glutamine synthetase (EC6.3.1.2) activity was measured in tissue homogenates as previously described with minor modifications [14]. Briefly, cerebral cortical and skeletal muscle samples were homogenised (20 wt\%/vol) using a Teflon pestle in Tris-EDTA buffer (pH 7.4), and homogenates were centrifuged at 10,000g for $10 \mathrm{~min}$. The supernatant $(0.1 \mathrm{~mL})$ was preincubated at $37^{\circ} \mathrm{C}$ for $10 \mathrm{~min}$ in an assay mixture containing $100 \mathrm{mM}$ imidazole (pH 7.2), $12.5 \mathrm{mM} \mathrm{MgCl}$, $20 \mathrm{mM}$ mercaptoethanol, $10 \mathrm{mM} \mathrm{ATP}, 4 \mathrm{mM}$ ammonium chloride, $13 \mathrm{mM}$ phosphoenolpyruvate, 50 units of pyruvate kinase and $0.16 \%$ Triton X-100. The reaction was started by adding $2 \mu \mathrm{Ci}$ of [1-14C]-glutamate (specific activity $60 \mathrm{mCi} / \mathrm{mmole}$, Perkin-Elmer, Boston, MA) diluted with cold glutamate to a final concentration of $50 \mathrm{mM}$ for skeletal muscle and $20 \mathrm{mM}$ for cerebral cortex. After incubation at $37^{\circ} \mathrm{C}$ for $60 \mathrm{~min}$ (30 min for muscle) the reaction was terminated by adding $1 \mathrm{~mL}$ ice-cold water and the mixture was immediately passed through a column $(3 \mathrm{~cm} \times 0.7 \mathrm{~cm})$ containing anion exchange resin (Dowex AG-1X8, acetate form). [1-14C]glutamate was quantitatively retained on the ion exchange column. Protein content of homogenates was determined by the method of Lowry [15]. Enzyme activities were expressed as micromoles of glutamine formed per hour per milligram of protein.

\section{GS gene expression (RT-PCR)}

\section{RNA extraction}

Total RNA was extracted using TRI Reagent (MRC Inc., Ohio) according to the manufacturer's protocol. Putative contaminating DNA was eliminated by adding $100 \mathrm{U}$ of RNase-free DNase I per $50 \mu \mathrm{g}$ of total RNA at $37^{\circ} \mathrm{C}$ for $1 \mathrm{~h}$. Purified RNA was then extracted with phenol, precipitated with ethanol and resuspended in diethylpyrocarbonatetreated water. RNA samples were stored at $-70{ }^{\circ} \mathrm{C}$ until use.

\section{RT-PCR analysis}

Glutamine synthetase expression was measured by the reverse transcription-polymerase chain reaction (RT-PCR) using the same forward and reverse primer sequences and reactions conditions as previously described [5].

\section{GS protein analysis (Western Blot)}

Tissue samples were homogenised in RIPA buffer (50 mM Tris- $\mathrm{HCl}$ (pH 8.0), $150 \mathrm{mM} \mathrm{NaCl}, 0.1 \%$ SDS, $1 \%$ Triton X$100,0.5 \%$ sodium deoxycholate), and a protease inhibitor mixture consisting of $1 \mathrm{mM}$ EDTA, $0.1 \mu \mathrm{M}$ pepstatin A, $1 \mu \mathrm{g} / \mathrm{ml}$ leupeptin, $1 \mu \mathrm{g} / \mathrm{ml}$ aprotinin, and $100 \mu \mathrm{g} / \mathrm{ml}$ phenylmethyl-sulfonyl fluoride. After centrifugation at $12,000 \mathrm{~g}$ for $15 \mathrm{~min}$, samples (50 $\mu \mathrm{g}$ protein) were boiled for $10 \mathrm{~min}$ in loading buffer (50 mM Tris-HCl, pH 6.8, 10\% glycerol; 2\% SDS, $0.1 \mathrm{M}$ dithiothreitol, $0.1 \%$ bromophenol blue). Proteins were resolved by $8 \%$ denaturing SDS- 
polyacrylamide gels and transferred overnight to nitrocellulose filters. Ponceau staining was used to ensure equal protein loading. The membranes were blocked for $2 \mathrm{~h}$ in Tris-buffered saline containing $5 \%$ dried milk and $0.1 \%$ Tween 20 (TBST), then incubated for $1 \mathrm{~h}$ with a monoclonal antibody directed against rat GS (Transduction laboratories, Lexington, KY). Blots were subsequently probed with anti-mouse horseradish peroxidase-conjugated antiserum (Roche Diagnostics, Indianapolis, IN) diluted 1/12,000 in the same buffer. After extensive washing with TBST, the peroxidase activity was detected by chemiluminescence using the Renaissance detection system (PerkinElmer, Boston, MA) and quantified by densitometric scanning.

\section{${ }^{1} \mathrm{H}^{13} \mathrm{C}$ Nuclear magnetic resonance spectroscopic studies}

Groups of hepatic devascularized rats $6 \mathrm{~h}$ post-HAL and their paired sham-operated controls were administered [U-

${ }^{13}$ ]C-glucose ( $400 \mathrm{mg} / \mathrm{kg}$, i.p.; Cambridge Isotope Laboratories, Andover, USA) and were killed exactly 20 min later by decapitation. Arterial blood glucose levels were continuously monitored and measured by mean of a glucometer using the glucose dehydrogenase method. Glucose was administered subcutaneously as needed to maintain normoglycemia. Immediately after sacrifice, samples of posterio-medial and lateral thigh muscle were snap-frozen, powdered over liquid nitrogen, and homogenized in $15 \mathrm{~mL}$ of a $12 \%$ PCA solution at $0{ }^{\circ} \mathrm{C}$ using a motor-driven polished glass tube-Teflon pestle homogenizer. The homogenate was centrifuged at $40,000 \mathrm{~g}$ for $15 \mathrm{~min}$; the supernatants were placed in an ice bath, and neutralized to $\mathrm{pH} 7.0$ with $\mathrm{KOH}$. The precipitated $\mathrm{KClO}_{4}$ was sedimented by centrifugation $(40,000 \mathrm{~g}$ for $15 \mathrm{~min}$ ), and supernatants were lyophilized. The lyophilized PCA extracts of muscle tissue were redissolved in 0.6-0.8 $\mathrm{ml}$ deuterium oxide $\left(\mathrm{D}_{2} \mathrm{O}\right)$ and centrifuged. Prior to analysis the $\mathrm{pH}$ was adjusted to 7.0 with deuterium chloride (DCl) and NaOD. ${ }^{1} \mathrm{H}-$ and ${ }^{13} \mathrm{C}$ NMR spectra were recorded on Bruker DRX 600 or AMX $360 / \mathrm{AM} 360$ spectrometers, operating at frequencies of 600 or $360 \mathrm{MHz}$ for ${ }^{1} \mathrm{H}$, and 150.9 or $90.5 \mathrm{MHz}$ for ${ }^{13} \mathrm{C}$ measurements.

${ }^{1} \mathrm{H}$ NMR spectra were recorded with a 5-mm H,C,N inverse triple resonance probe, 400 accumulations, repetition time 15 s, spectral width $7183 \mathrm{~Hz}$ (DRX 600) or $3623 \mathrm{~Hz}$ (AM/AMX 360), data size $16 \mathrm{~K}$, zero filling to $32 \mathrm{~K}$. Chemical shifts were referenced to lactate at $1.33 \mathrm{ppm}$.

${ }^{13} \mathrm{C}$ NMR spectra were recorded with a $5-\mathrm{mm}{ }^{1} \mathrm{H} /{ }^{13} \mathrm{C}$ dual probe, 10,000 accumulations, repetition time $2.5 \mathrm{~s}$, composite pulse decoupling with WALTZ-16, spectral width 47,619 Hz (DRX 600) or 20,833 Hz (AM/AMX 360), data size $32 \mathrm{~K}(16 \mathrm{~K})$, zero filling to $64 \mathrm{~K}(32 \mathrm{~K})$. Chemical shifts were referenced to the $\mathrm{C}-3$ signal of lactate at $21.3 \mathrm{ppm}$.

Glutamine concentrations ( $\mu \mathrm{mol} / \mathrm{g}$ tissue) were determined from fully relaxed ${ }^{1} \mathrm{H}$ NMR spectra of muscle extracts using (trimethylsilyl)propionic-2,2,3,3,d4-acid as an external standard. Fractional enrichment in glutamine (C3 position) a measure of de novo glutamine synthesis was calculated from 13C NMR spectra as previously described [16].

\section{Statistical analysis of data}

Data were analyzed by unpaired $t$-test. In cases where the variances between compared groups were significantly different, the unpaired $t$-test was modified with Welch's correction. The data were considered to be significantly different at $P<0.05$.

\section{RESULTS}

\section{Effect of ALF on plasma ammonia and glutamine levels}

Plasma ammonia and glutamine levels in ALF rats are shown in Table 1. ALF resulted in a significant 16.5-fold $(\mathrm{P}<0.001)$ increase of arterial ammonia levels $6 \mathrm{~h}$ post-HAL compared to sham-operated control values. Arterial glutamine levels were concomitantly increased 6.7-fold $(P<0.001)$ in the ALF animals. 
Chatauret, N. et al., 2006. Direct molecular and spectroscopic evidence for increased ammonia removal capacity of skeletal muscle in acute liver failure. Journal of Hepatology, 44(6), p.1083-1088.

Table 1. Arterial plasma levels, $\mathrm{A}-\mathrm{V}$ differences, muscle ammonia and glutamine fluxes, and hemodynamics in the hind limb of rats with acute liver failure compared to sham-operated controls

\begin{tabular}{lcc}
\hline & Sham-operated controls & ALF \\
\hline Arterial levels $(\mu \mathrm{M})$ & & \\
$\quad$ Ammonia & $33.0 \pm 5.8$ & $533.1 \pm 35.7^{* *}$ \\
$\quad$ Glutamine & $604 \pm 33$ & $3870 \pm 220^{* * *}$ \\
A-V differences $(\mu \mathrm{M})$ & $19.8 \pm 5.8$ & $103.9 \pm 14.2^{* *}$ \\
$\quad$ Ammonia & $-84.5 \pm 20.9$ & $-431.8 \pm 75.6^{*}$ \\
$\quad$ Glutamine & $9.3 \pm 2.4$ & $11.8 \pm 1.8$ \\
Hemodynamics & $9.3 \pm 2.0$ & $26.8 \pm 2.5^{* * *}$ \\
$\quad$ Mean percentage difference in blood flow between the left and right kidneys $(\%)$ & $0.22 \pm 0.12$ & $2.76 \pm 0.51^{*}$ \\
$\quad$ Muscle blood flow (mL/min per 100 g of muscle) & $-0.91 \pm 0.33$ & $-12.18 \pm 2.22^{* *}$ \\
Muscle fluxes ( $\mu \mathrm{mol} / \mathrm{min}$ per 100 $\mathrm{g}$ of muscle) & \\
$\quad$ Ammonia &
\end{tabular}

Values represent mean \pm SEM of eight rats per treatment group. Values significantly different from sham-operated group are indicated by: ${ }^{*} P<0.01$ and ${ }^{* *} P<0.001$.

\section{Effect of ALF on GS gene expression, protein and activity in skeletal muscle and brain}

ALF resulted in a significant increase of GS protein in skeletal muscle (Fig. 1A and B) and a small but significant loss of GS protein in brain (frontal cortex) 6 h post-HAL compared to sham-operated controls $(P<0.05)$. GS mRNA was unchanged following ALF (data not shown).

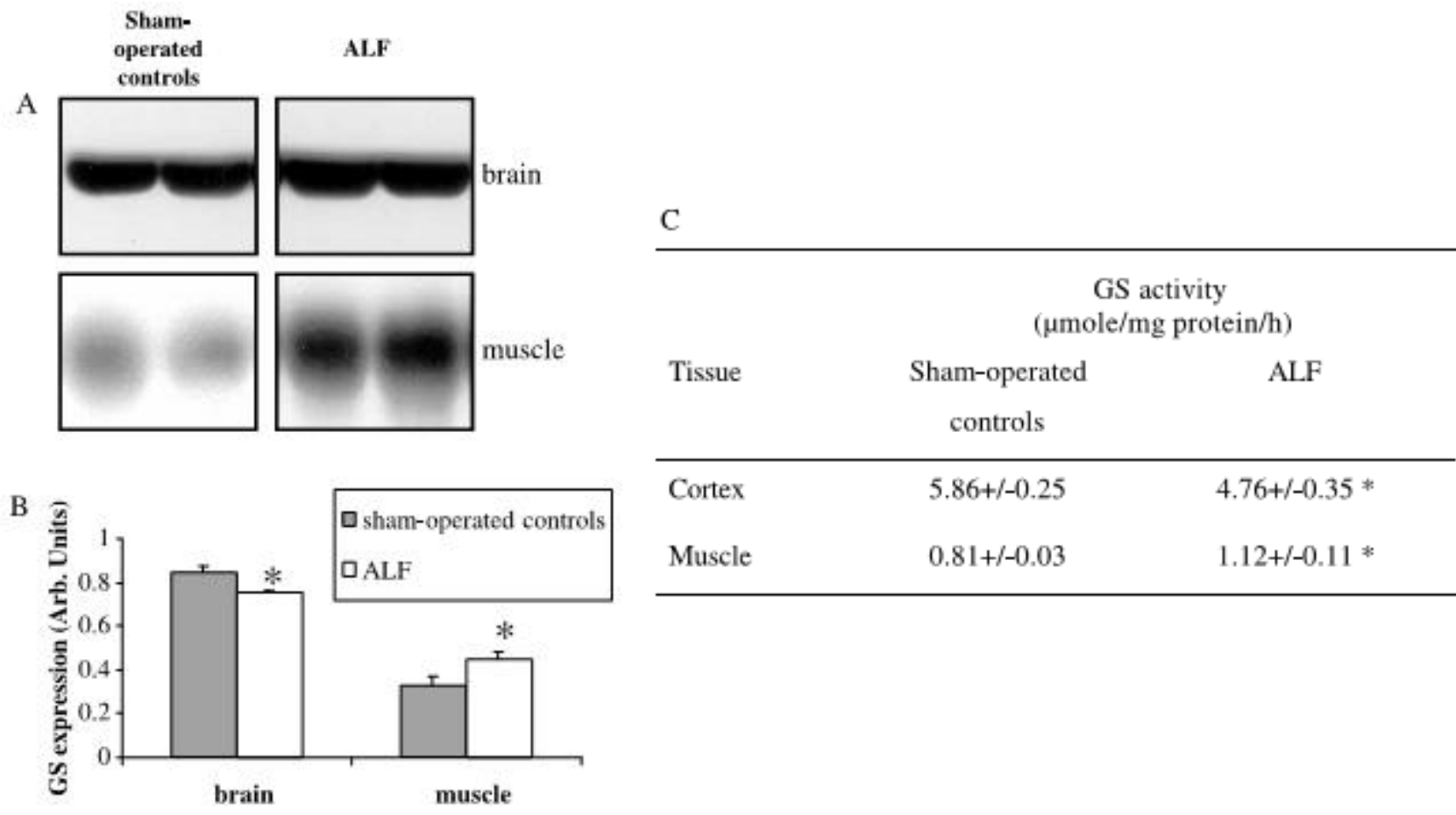

Fig. 1. GS protein and enzyme activities in brain (cerebral cortex) and skeletal muscle of rats with ALF. (A)

Representative Western blots of GS (45 kDa) from two ALF rats compared to sham-operated controls. (B) GS protein data from $n=8$ animals per treatment group. (C) GS enzyme activities determined in cerebral cortex and skeletal muscle of eight ALF rats compared to eight sham-operated controls. Values represent mean $\pm \mathrm{SE}$, * indicates values significantly different from sham-operated control values $(P<0.05)$. 
Changes in GS enzyme activities paralleled those of GS protein: ALF resulted in a $38 \%$ increase $(P<0.05)$ in GS enzyme activities in skeletal muscle $6 \mathrm{~h}$ post-HAL (Fig. 1C). In contrast, a small but significant loss $(P<0.05)$ of GS activity was observed in the cerebral cortex of ALF animals at the same time point.

\section{Arterio-venous differences across skeletal muscle of ALF rats}

Sham operated control rats manifested significantly lower ammonia concentrations in the femoral vein compared to the femoral artery leading to an A-V difference of 19.8 $\pm 5.8 \mu \mathrm{M}$. This A-V difference was increased five-fold $6 \mathrm{~h}$ postHAL in the HAL group $(103.9 \pm 14.2 \mu \mathrm{M} ; \mathrm{P}<0.001)$ (Table 1$)$. These positive $A-V$ differences for ammonia across the hind limb of control animals were accompanied by a significant release of glutamine (A-V difference of $-84.5 \pm 20.9 \mu \mathrm{M}$ ). This A-V difference for glutamine was significantly increased 5 -fold $6 \mathrm{~h}$ post-HAL in the ALF group $(-431.8 \pm 75.6 \mu \mathrm{M}, \mathrm{P}<0.01)$ (Table 1).

\section{Effect of ALF on muscle blood flow and on fluxes of glutamine and ammonia across the hind limb}

Values for muscle blood flow are presented in the Table 1. Variation of renal blood flow between the right and left kidney were less than $20 \%$ and differences between the two treatment groups were not significant indicating that the procedure used was valid. There was a significant $188 \%(\mathrm{P}<0.01)$ increase in muscle blood flow $6 \mathrm{~h}$ post-HAL compared to sham operated control values.

Uptake of ammonia across the hind limb was significantly increased in ALF rats compared to sham-operated controls $(2.76 \pm 0.51 \mu \mathrm{mol} / \mathrm{min}$ per $100 \mathrm{~g}$ of muscle versus $0.22 \pm 0.11 \mu \mathrm{mol} / \mathrm{min}$ per $100 \mathrm{~g} ; \mathrm{P}<0.01)$ (Table 1$)$. Glutamine release by the hind limb was concomitantly increased from $-0.91 \pm 0.33 \mu \mathrm{mol} / \mathrm{min}$ per $100 \mathrm{~g}$ of tissue in control rats to $-12.18 \pm 2.22 \mu \mathrm{mol} / \mathrm{min}$ per $100 \mathrm{~g}$ of tissue in ALF rats $(P<0.001)$.

\section{Effect of ALF on de novo glutamine synthesis in skeletal muscle}

${ }^{1} \mathrm{H} /{ }^{13} \mathrm{C}$ NMR measurements revealed a significant 73.4\% $(\mathrm{P}<0.0001)$ increase in muscle glutamine levels $6 \mathrm{~h}$ postHAL compared to sham-operated controls (Fig. 2A and B). Increased muscle glutamine levels were accompanied by significant $61 \%(\mathrm{P}<0.01)$ increase in $13 \mathrm{C}$ glutamine labeling from $[\mathrm{U}-13 \mathrm{C}]$ glucose indicating increased de novo glutamine synthesis (Fig. 2B).

B

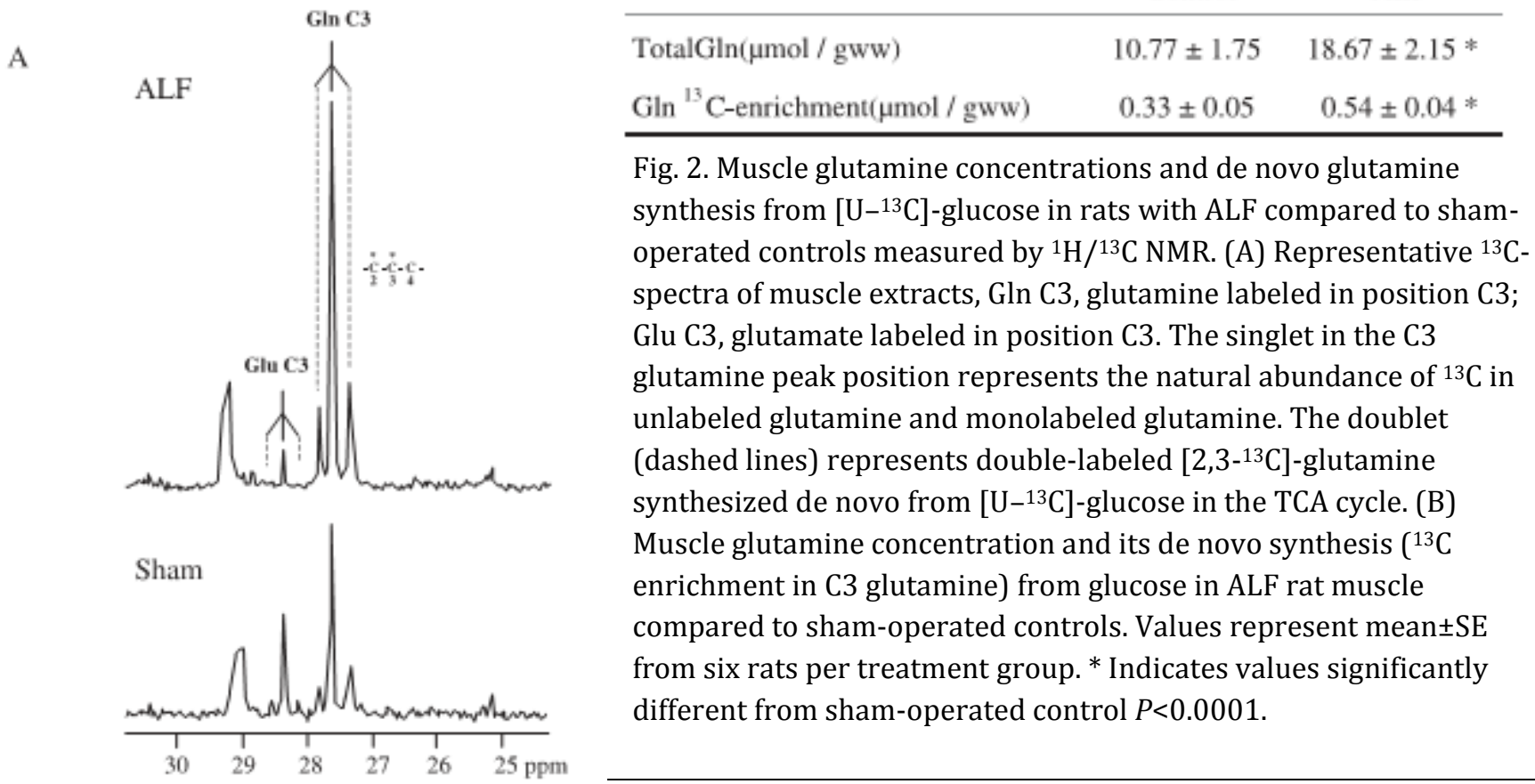

The final publication is available at http://dx.doi.org/10.1016/j.jhep.2005.11.048 


\section{DISCUSSION}

Results of the present study provide the first unequivocal evidence in support of the notion that skeletal muscle ammonia removal capacity is increased in ALF. This increase occurs as a consequence of an early posttranscriptional increase in expression of glutamine synthetase (GS) a cytosolic enzyme (Fig. 3) that is predominantly responsible for ammonia removal by skeletal muscle which is devoid of an effective urea cycle. Glutamine synthetase activities were increased by 40\% early during the progression of ALF and 13C Nuclear Magnetic Resonance Spectroscopic studies revealed that this led to a significant increase in de novo synthesis of glutamine by skeletal muscle. These findings confirm and extend those of a previous study based upon a report of increased ammonia removal and glutamine release in the femoral vein in patients with ALF [17].

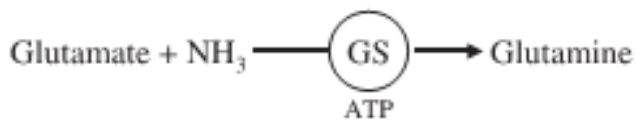

Fig. 3. Schematic representation of the glutamine synthesis reaction in muscle and brain.

In the present study, induction of GS protein and enzyme activities led to a significant decrease in arterio-venous differences for glutamine. Muscle blood flow was concomitantly increased 2.7-fold consistent with the wellestablished hyperdynamic circulation characteristic of ALF. An accurate measurement of muscle ammonia and glutamine fluxes requires measurement of arterio-venous differences corrected for change in organ blood flow. Such a computation in the present study reveals a 12-fold uptake of ammonia and a corresponding increase of muscle glutamine release from skeletal muscle. That these findings represent principally increased glutamine synthesis in skeletal muscle was confirmed by studies with ${ }^{13} \mathrm{C}$ NMR which showed unequivocally that de novo synthesis of glutamine was significantly increased. However, since glutamine de novo synthesis is less than total glutamine release from muscle, synthesis of glutamine from other sources of carbon than glucose or muscle protein breakdown cannot be ruled out.

In contrast to skeletal muscle, results of the present study clearly demonstrate that, GS protein expression and enzyme activities in brain manifest small but statistically significant reductions $6 \mathrm{~h}$ following hepatic devascularization. A possible explanation for these findings has recently emerged. Exposure of cultured rat astrocytes (the cells that express GS in the brain) to pathophysiologically relevant (low millimolar) concentrations of ammonia results in significant nitration of GS on the tyrosine residues [18] leading to a significant reduction of GS activity. Whether, or not similar mechanisms are responsible for the loss of brain GS expression in ALF awaits the results of ongoing studies. These findings of a lack of induction of brain GS in ALF again underscores the brain's lack of an adequate protective mechanism against ammonia toxicity.

In conclusion, ALF resulting from hepatic devascularization in the rat results in an early increase in GS activity in skeletal muscle, an increase that results from post-transcriptional change in GS protein. Spectroscopic studies confirm that this increase in activity results in increased de novo synthesis of glutamine in the muscle and studies of arterio-venous differences corrected for muscle blood flow reveal significant increases of muscle glutamine release. Initial studies suggest that similar mechanisms occur in ALF patients. If confirmed, these findings suggest that the maintenance of skeletal muscle mass and the use of agents with the potential to stimulate GS activity in skeletal muscle could be useful in the reduction of circulating ammonia and the prevention of the cerebral complications of ALF. 
Chatauret, N. et al., 2006. Direct molecular and spectroscopic evidence for increased ammonia removal capacity of skeletal muscle in acute liver failure. Journal of Hepatology, 44(6), p.1083-1088.

\section{REFERENCES}

[1] J.O. Clemmesen, F.S. Larsen, J. Kondrup, B.A. Hansen, P. Ott Cerebral herniation in patients with acute liver failure is correlated with arterial ammonia concentration Hepatology, 29 (1999), pp. 648-653

[2] J.C. Szerb, R.F. Butterworth Effect of ammonium ions on synaptic transmission in the mammalian central nervous system Prog Neurobiol, 39 (1992), pp. 135-153

[3] O.P. Ganda, N.B. Ruderman Muscle nitrogen metabolism in chronic hepatic insufficiency Metabolism, 25 (1976), pp. 427-435

[4] G. Girard, R.F. Butterworth Effect of portacaval anastomosis on glutamine synthetase activities in liver, brain, and skeletal muscle Dig Dis Sci, 37 (1992), pp. 1121-1126

[5] P. Desjardins, K.V. Rao, A. Michalak, C. Rose, R.F. Butterworth Effect of portacaval anastomosis on glutamine synthetase protein and gene expression in brain, liver and skeletal muscle Metab Brain Dis, 14 (1999), pp. 273-280

[6]A.T. Blei, A. Omary, R.F. Butterworth Animal models of hepatic encephalopathy A.A. Boulton, G.B. Baker, R.F. Butterworth (Eds.), Animal models of neurological diseases II, neuromethods, Human Press, Totowa (1992), pp. 183-222

[7] S.H. Lee, B. Fisher Portacaval shunt in the rat Surgery, 50 (1961), pp. 668-672

[8]N. Chatauret, C. Rose, G. Therrien, R.F. Butterworth Mild hypothermia prevents cerebral edema and CSF lactate accumulation in acute liver failure Metab Brain Dis, 16 (2001), pp. 95-102

[9] S. Yang, C.S. Chung, A. Ayala, I.H. Chaudry, P. Wang Differential alterations in cardiovascular responses during the progression of polymicrobial sepsis in the mouse Shock, 17 (2002), pp. 55-60

[10] M.A. Heymann, B.D. Payne, J.I. Hoffman, A.M. Rudolph Blood flow measurements with radionuclide-labeled particles Prog Cardiovasc Dis, 20 (1977), pp. 55-79

[11] M.A. Heymann, B.D. Payne, J.I. Hoffman, A.M. Rudolph Blood flow measurements with radionuclide-labeled particles Prog Cardiovasc Dis, 20 (1977), pp. 55-79

[12] S.G. Dienst An ion exchange method for plasma ammonia concentration J Lab Clin Med, 58 (1961), pp. 149-155

[13] A. Michalak, C. Rose, J. Butterworth, R.F. Butterworth Neuroactive amino acids and glutamate (NMDA) receptors in frontal cortex of rats with experimental acute liver failure Hepatology, 24 (1996), pp. 908-913

[14] G. Girard, R.F. Butterworth Effect of portacaval anastomosis on glutamine synthetase activities in liver, brain, and skeletal muscle Dig Dis Sci, 37 (1992), pp. 1121-1126

[15] 0.H. Lowry, N.J. Rosebrough, A.L. Farr, R.J. Randall Protein measurement with the Folin phenol reagent J Biol Chem, 193 (1951), pp. 265-275

[16] C. Zwingmann, N. Chatauret, D. Leibfritz, R.F. Butterworth Selective increase of brain lactate synthesis in experimental acute liver failure: results of a [H-C] nuclear magnetic resonance study Hepatology, 37 (2003), pp. 420-428

[17] J.O. Clemmesen, J. Kondrup, P. Ott Splanchnic and leg exchange of amino acids and ammonia in acute liverailure Gastroenterology, 118 (2000), pp. 1131-1139

[18] F. Schliess, B. Gorg, R. Fischer, P. Desjardins, H.J. Bidmon, A. Herrmann et al. Ammonia induces MK-801-sensitive nitration and phosphorylation of protein tyrosine residues in rat astrocytes Fed Am Soc Eur Biol J, 16 (2002), pp. 739-741

The final publication is available at http://dx.doi.org/10.1016/i.jhep.2005.11.048 